\title{
PENINGKATAN TPACK GURU FISIKA MELALUI MEDIA PEMBELAJARAN BERBASIS GOOGLE APPS
}

\author{
Ayu Amelia1, Erfin Nurfalah', Diah Mulhayatiah' ${ }^{1}$ \\ 1 Program Studi Pendidikan Fisika, Fakultas Tarbiyah dan Keguruan, UIN Sunan Gunung Djati \\ Bandung, Indonesia \\ E-mail:ayuayuamel@gmail.com.
}

\begin{abstract}
ABSTRAK
Pada abad ke-21 teknologi merupakan suatu hal yang penting dalam sebuah pembelajaran. Kemampuan yang perlu dimiliki guru untuk menyiapkan peserta didik pada abad 21 ini adalah kemampuan TPACK. Kemampuan TPACK penting dimiliki oleh seorang guru untuk memadukan teknologi dengan pedagogik dan pengetahuannya tentang konten Fisika. Tujuan dari penelitian ini adalah untuk mengetahui peningkatan kemampuan TPACK seorang guru menggunakan media pembelajaran berbasis google apps. Metode yang digunakan adalah tinjauan pustaka dengan menganalisis enam artikel yang paling relevan. Hasil dari kajian pustaka tersebut menjelaskan bahwa kemampuan TPACK ini perlu dimiliki oleh seorang guru dalam pembelajaran karena didalamnya sudah terpadu antara pedagogik, pengetahuan, dan teknologinya. Namun pada kenyataannya seorang guru masih belum memiliki kemampuan tersebut. Google Apps dapat digunakan untuk meningkatkan kemampuan TPACK guru karena penggunaan google apps dalam pembelajaran lebih efektif dan hasilnya pun lebih baik daripada pembelajaran yang tidak menggunakan media google apps.
\end{abstract}

Kata kunci: Google Apps, Kemampuan TPACK, Media,

\begin{abstract}
In the 21st century, technology is an important thing in learning. The ability that teachers need to have to prepare student in the $21^{\text {st }}$ century is the TPACK ability. It is important for a teacher to have TPACK's ability to combine technology with pedagogy and content knowledge of physics. The purpose of this study is to determine the improvement of a teacher's TPACK ability using based learning media google apps. The method used was literature review by analyzing the six most relevant articles. The results of the literature review explain that this TPACK ability needs to be possessed by a teacher in learning because it is integrated between pedagogy, knowledge, and technology. However, most teachers still don't have this ability. Google Apps can be used to improve the TPACK ability of teachers because the use of google apps in learning is more effective and the results are better for learning that does not use media google apps.
\end{abstract}

Keywords: Google Apps, Media, and TPACK Capability

DOI: http://dx.doi.org/10.15575/jotalp.v6i2.10298

Received: 25 November 2020 ; Accepted: 3 Agustus 2021 ; Published: 31 Agustus 2021 


\section{PENDAHULUAN}

Peraturan Menteri Pendidikan Nasional Nomor 16 Tahun 2007 Tentang Standar Kualifikasi Akademik dan Kompetensi, yang mana seorang guru memanfaatkan teknologi dan komunikasi untuk kepentingan pembelajaran (Sole \& Anggraeni, 2018). Pembelajaran merupakan suatu proses yang membuat orang belajar. Belajar merupakan usaha untuk mengubah tingkah laku yang dilakukan melalui suatu proses yang berlangsung di dalam diri seseorang untuk mengubah tingkah lakunya, baik tingkah laku dalam berpikir, bersikap, maupun berbuat (Gora \& Sunarto, 2010).

Pada abad 21 seorang guru perlu memiliki keterampilan teknologi, hal itu dikarenakan semakin berkembangnya teknologi pada abad ini yang menuntut guru untuk memiliki pengetahuan tentang teknologi dan penggunaannya dalam pembelajaran. Peran guru dalam melaksanakan pembelajaran abad ke-21 sangat penting dan berpengaruh dalam mewujudkan masa depan anak bangsa yang lebih baik. Guru tidak hanya sebagai pengajar yang mentransfer ilmu saja, melainkan perlu memiliki keterampilan yang efektif, diantaranya keterampilan guru abad-21 adalah life and career skills (kecakapan hidup dan berkarir) yang artinya guru dapat mengatur diri sendiri, interaksi sosial dan budaya, produktif serta memiliki jiwa kepemimpinan dan tanggungjawab.

Keterampilan lain adalah learning and innovation skills yang meliputi berpikir kritis dalam menagatasi masalah serta mampu berkomunikasi. Terakhir adalah information media and technology skills (keterampilan teknologi dan media informasi) yang meliputi literasi media, dan memiliki kemampuan teknologi. Guru harus mempersiapkan peserta didik agar memiliki keterampilan abad ke-21 (Yulianisa, Rizal, Oktaviani, \& Abdullah, 2018, pp. 3-4).

Peserta didik dituntut memiliki kompetensi yakni Critical Thinking and Problem Solving (berpikir kritis dan menyelesaikan masalah), Creativity (kreativitas), Communication Skills (kemampuan berkomunikasi), dan Ability to Work Collaboratively (kemampuan berkolaborasi). Seorang guru perlu menguasai berbagai bidang diantaranya dalam hal pedagogik termasuk inovasi dalam pengajaran dan pembelajaran serta mampu memanfaatkan media dan teknologi baru dalam pembelajaran. (Hadisaputra, Hadiprayitno, Hakim, \& Muhlis, 2018). Pemilihan teknologi pada setiap pelajaran harus tepat dan sesuai agar mencapai hasil belajar yang memuaskan dan sesuai dengan tujuan pembelajaran.

Kegiatan pembelajaran sepenuhnya diatur oleh seorang guru, yang mana guru harus mengatur strategi, teknologi, media yang akan digunakan untuk menyampaikan informasi dan memandu proses belajar bagi peserta didik. Pemahaman tentang pembelajaran akan menentukan filosofi yang dianut dan media pembelajaran yang digunakan. Teknologi dan media merupakan peranan penting dalam pembelajaran. Media dapat digunakan untuk mendukung pengajaran yang dilakukan oleh guru dalam kapasitas pengajaran yang berpusat pada guru dan peserta didik bertindak sebagai pengguna teknologi atau media tersebut dalam kapasitas pengajaran yang berpusat pada peserta didik. Guru dapat memanfaatkan media pembelajaran sebagai salah satu komponen untuk menunjang pembelajaran yang berpusat pada peserta didik. Efektivitas penggunaan media bergantung pada perencanaan dan pemilihan media yang sesuai dengan materi karena seorang guru harus mengetahui karakteristik berbagai macam media yang digunakan (Dewi \& Budiana, 2018).

Menurut Saraswati (2020), perkembangan teknologi yang semakin pesat memberikan andil yang sangat besar pada perkembangan ilmu pengetahuan, terkhusus dalam pemanfaatan dalam pembelajaran yaitu media pembelajaran. Media pembelajaran dikatakan faktor penting dalam sistem pembelajaran, karena penggunaan media pembelajaran dapat mengatasi kendala ataupun keterbatasan dalam penyampaian materi di kelas (Saraswati, 2019, p. 26)

Menurut Asyari dan Silvia (2016), media pembelajaran merupakan faktor yang mendukung keberhasilan proses pembelajaan 
di sekolah karena dapat membantu proses penyampaian informasi dari guru kepada siswa ataupun siswa kepada guru. Banyak macam media pembelajaran yang dapat digunakan serta manfaat yang banyak pula. Penggunaan media pembelajaran harus didasarkan pada pemilihan yang tepat. Pembelajaran dengan menggunakan media pembelajaran tidak hanya sekedar penyampaian dengan kata-kata melainkan suatu alat yang dapat digunakan untuk perantara menyalurkan isi pelajaran atau materi yang disampaikan agar peserta didik mudah untuk memahami materi yang disampaikan oleh guru (Asyhari \& Silvia, 2016). Salah satu pemanfaatan media pembelajaran di era digital ini adalah Google Apps for Education.

Google Apps for Education merupakan layanan yang diberikan oleh Google untuk sebuah lembaga pendidikan, layanan yang diberikan meliputi Gmail, Google Docs, Google Form, dan yang lainnya. Layanan yang diberikan oleh google terbukti banyak membantu Lembaga Pendidikan dalam proses pembelajaran. Maury dan Daniel (2015) telah melakukan penelitian kepada peserta didik yang menggunakan Google Apps for Education dengan hasil yang menunjukkan bahwa Google Apps ini relatif mudah digunakan untuk pembelajaran bahkan untuk pengguna baru. Hal tersebut terbukti karena Google Apps dapat membantu proses pembelajaran yang dilakukan secara tidak langsung. Interaksi antara guru dengan peserta didik tidak hanya terbatas dengan ruangan kelas, namun dapat diakses melalui media ini (Brown, 2015).

Penelitian lain yang dilakukan oleh Hermanto dan Harimurti (2017) menunjukan hasil bahwa pembelajaran menggunakan Google Apps lebih baik daripada siswa yang tidak menggunakan Google Apps for Education. Hal tersebut dibuktikan dengan diterapkannya media Google Apps pada suatu pembelajaran, dan dibandingakan dengan pembelajaran yang tidak menggunakan media tersebut, dan hasilnya lebih baik pembelajaran menggunakan media Google Apps (Hermanto \& Harimurti, 2017).
Penggunaan media pembelajaran pada setiap pembelajaran dapat mengukur kemampuan guru dalam mengelola pembelajaran, baik secara pedagogik, konten, pengetahuan, dan teknologi. Kemampuan guru dalam menggunakan teknologi yang didasarkan pada analisis karakter materi dan analisis pada aspek pedagogik disebut dengan TPACK (Technological Pedagogical Content Knowledge). TPACK merupakan penggabungan antara teknologi, pedagogik, dan konten yang diterapkan sesuai dengan konteks dalam pembelajaran. Penggabungan tersebut harus dikuasai semuanya oleh guru. Kerangka TPACK menjelaskan tiga pengetahuan yang ditambah dengan unsur teknologi, yaitu Technological Knowledge (TK), Technological Content Knowledge (TCK), dan Technological Pedagogical (TP). Ketiga pengetahuan beserta teknologi tersebut penting dimiliki seorang guru, karena mempengaruhi cara mengajar suatu materi (Suryawati, Linggasari, \& Arnentis, 2017). Kemampuan seorang guru saat mengajar dipengaruhi oleh kemampuan TPACK guru itu sendiri. Berdasarkan studi yang dilakukan oleh Supriyadi,dkk (2018) mengatakan bahwa kemampuan TPACK guru diawali dengan pemberian pengetahuan awal tentang model dan metode pembelajar yang kreatif dan inovatif. Selanjutnya guru diberi kebebasan dalam menentukan topik materi, metode dan model pembelajaran yang digunakan serta teknologi sebagai media dalam proses pembelajaran (Supriyadi, Bahri, \& Waremra, 2018).

Technological Pedagogical Content Knowledge (TPACK) bukan hanya sekedar memahami teknologi, konten, dan pedagogik secara terpisah, melainkan sebagai bentuk yang muncul untuk memahami bagaimana ketiga komponen yang ada didalam TPACK ini saling berinteraksi. TPACK mengacu pada pemahaman tentang bagaimana mempresentasikan konsep dengan bantuan teknologi, teknik pedagogik dengan bantuan teknologi dengan cara yang konstruktif untuk mengajarkan konten materi fisika pada peserta didik (Nasar \& Daud, 2020). 


\section{METODE PENELITIAN}

Metode yang digunakan pada penelitian ini adalah kajian pustaka yang merupakan kajian teori yang relevan dengan topik yang akan diteliti.

Proses kajian pustaka dimulai dengan mengidentifikasi artikel yang paling relevan dengan topik penelitian. Kata kunci pada dalam pencarian artikel untuk tinjauan pustaka ini adalah kemampuan TPACK guru, media pembelajaran, dan google apps. Pada penelitian ini peneliti menghasilkan 10 artikel yang berpotensi untuk direview.

\section{HASIL DAN PEMBAHASAN}

Artikel yang menjadi referensi utama pada penelitian ini didapatkan 10 artikel yang berpotensi untuk direview. Dari 10 jurnal yang ada terpilih 6 jurnal yang paling relevan untuk dan memenuhi kriteria inklusi kajian pustaka ini.

Artikel yang akan dikaji merupakan terbitan dari 2015-2020. Tiga artikel membahas tentang kemampuan TPACK guru dan tiga lainnya membahas tentang penggunaan google apps dalam pembelajaran. Adapun hasil dari analisis lebih lanjut dari enam jurnal yang paling relevan terdapat dalam Tabel 1.

Tabel 1 Hasil Kajian Pustaka Artikel

No

\author{
Hasil Analisis
}

Penulis: Imam Fitri Rahmadi, 2019

Judul: Technological Pedagogical Content Knowledge (TPACK): Kerangka Pengetahuan Guru Abad 21

Metode: Kajian pustaka dari buku, jurnal dan dokumen lain yang berkaitan dengan tema yang relevan.

Hasil: TPACK merupakan salah satu jenis pengetahuan baru yang harus dikuasai guru untuk dapat mengintegrasikan teknologi dengan baik dalam pembelajaran, pengukuran TPACK merupakan aktivitas penilaian terhadap tingkat penguasaan TPACK yang dilakukan menggunakan framework TPACK, dan pengembangan TPACK merupakan kelanjutan dari proses pengukuran yang dilakukan untuk meningkatkan penguasaan TPACK.

Penulis: Adrianus Nasar dan Maomunah H.Daud, 2020

Judul: Analisis Kemampuan Guru IPA tentang TPACK pada SMP/MTs di Kota Ende

Metode: Metode yang digunakan dalam penelitian ini adalah survei dengan memberi angket kepada guru-guru.

Hasil: Hasil penelitian menunjukkan bahwa tingkat komponen TPACK guru IPA SMP/MTs di kota Ende berada pada tingkat cukup tinggi dan tinggi.

Penulis: Andi Reski dan Desy Kumala Sari, 2020

Judul: Analisis Kemampuan TPACK Guru Fisika Se-Distrik Merauke

Metode: Metode yang digunakan adalah metode survei. Data yang dianalisis merupakan data yang diambil dari populasi yang diteliti. Metode survei yang digunakan adalah metode survei deskriptif.

Hasil: Hasil penelitian menunjukkan bahwa guru fisika se-distrik Merauke belum mampu menyelenggarakan pembelajaran fisika yang berbasis teknologi informasi dan komunikasi (TIK) yaitu pembelajaran yang memadukan pengetahuan konten dan pedagogik dengan teknologi.

Penulis: Maury Elizabeth dan Daniel I. Hocutt, 2015

Judul: Learning to Use, Useful for Learning: A Usability Study of Google Apps for Education

Metode: Literature Review sesuai dengan tema yang berkaitan.

$4 \quad$ Hasil: Hasil studi menunjukkan bahwa Google Apps ini relatif mudah digunakan bahkan untuk pengguna baru. Maka dari itu disarankan kepada guru untuk memperkenalkan Google Apps ini kepada siswa untuk meningkatkan kemampuan pedagogic guru, dan kemampuan dadam menggunakan teknologi dalam pembelajaran. 
Penulis: Felixtian Teknowijoyo, 2020

Judul: Media Pembelajaran Berbasis Google Edukasi untuk Meningkatkan Hasil Belajar Peserta Didik pada Pelajaran Fisika di SMP

$5 \quad$ Metode: Metode penulisan artikel ini dengan kajian literatur jurnal penelitian yang relevan.

Hasil: Dengan menggunakan pembelajaran berbasis google education peserta didik akan dengan aktif memahami konsep-konsep Fisika, yang melibatkan komunikasi dan kolaborasi antar peserta didik, sehingga meningkatkan kemampuan berpikir kritis dan hasil belajar peserta didik.

Penulis: Rahmat Hermanto dan Rina Harimurti, 2017

Judul: Pembelajaran Student Centered Learning berbasis Media Pembelajaran Google for Education untuk meningkatkan Hasil Belajar Siswa pada Bidang Kejuruan Multimedia SMKN 3 Surabaya.

Metode: Metode penelitian yang digunakan adalah kuasi eksperimental menggunakan desain pendekatan. Subjek penelitiannya adalah desain eksperimental dengan menggunakan Pretest Posttest.

Hasil: Dengan menggunakan pretest dan posttest didapatkan hasil bahwa pembelajaran menggunakan Google Apps lebih baik daripada siswa yang tidak menggunakan Google Apps for Education.

Dari Tabel 1 didapatkan bahwa seorang guru harus memiliki kemampuan TPACK yang merupakan jenis pengetahuan untuk mengintegrasikan teknologi dalam pembelajaran yang dapat dijadikan sebagai kerangka kerja untuk mendesain kurikulum guru yang sesuai dengan tuntutan pembelajaran abad ke-21 (Rahmadi, 2019, p. 66). Penelitian yang dilakukan (Nasar \& Daud, 2020) menghasilkan bahwa kemampuan TPACK berada pada tingkatan yang cukup tinggi, itu artinya masih ada guru yang belum memiliki kemampuan TPACK. Menurut penelitian yang dilakukan (Reski \& Sari, 2020) mengatakan bahwa guru fisika se-distrik Merauke belum mampu menerapkan pembelajaran berbasis teknologi, dan belum menguasai keterampilan TPACK guru.

Menurut (Brown, 2015) Google Apps merupakan salah satu media yang dapat digunakan dalam pembelajaran yang relatif mudah digunakan untuk pengguna baru. Penggunaan media google apps ini dapat meningkatkan kemampuan TPACK seorang guru karena memanfaatkan teknologi dalam pembelajaran. Google Apps selain mudah digunakan juga dapat memudahkan peserta didik memahami konsep fisika dengan melibakan komunikasi dan kolaborasi agar meningkatkan kemampuan berpikir kritis dan hasil belajar peserta didik (Teknowijoyo, 2020). Penggunaan google apps yang dibandingkan dengan pembelajaran ceramah berdasarkan penelitian (Hermanto \& Harimurti, 2017) mengatakan bahwa hasil pembelajaran menggunakan google apps lebih baik daripada tidak menggunakan media google apps.

\section{Kemampuan TPACK Guru}

\section{Technological Pedagogical Content Knowledge} (TPACK) merupakan salah satu jenis pengetahuan baru yang harus dimiliki seorang guru untuk dapat mengingtegrasikan teknologi dalam pembelajaran dengan baik (Koehler \& Mishra, 2009).

TPACK terbentuk atas perpaduan tiga jenis pengetahuan dasar, yaitu Technological Knowledge (TK) yang merupakan kemampuan untuk mengadaptasi dan mempelajari teknologi untuk keberlangsungan pembelajaran, Pedagogical Knowledge (PK) adalah kemampuan yang mendeskripsikan pengetahuan dari berbagai macam metode yang digunakan, meliputi bagaimana mengorganisasikan aktivitas di kelas, serta Content Knowledge (CK) yang merupakan pengetahan disiplin ilmu pada materi/konten yang harus dikuasi guru (Rosyid, 2016). 
Pengetahuan dasar tersebut menghasilkan empat pengetahuan baru, yaitu Pedagogical Content Knowledge (PCK) merupakan pengajaran efektif yang memerlukan lebih dari sekedar pemahaman konten dan pedagogik. Pedagogical Content Knowledge yang dimiliki guru berkesinambungan dengan efektivitas dan hasil belajar peserta didik. Kemampuan PCK penting dimiliki seorang guru fisika, karena seorang guru fisika harus menguasai konten fisika dan memamahi pedagogik atau cara membantu peserta didik memecahkan masalah dalam pembelajaran (Chotimah \& Hariyatmi, 2017). Technological Content Knowledge (TCK) merupakan pengetahuan dari hubungan timbal balik antara teknologi dan konten pembelajaran. Technological Pedagogical Knowledge (TPK) merupakan hubungan timbal balik antara teknologi dengan pedagogik untuk memahami penggunaan teknologi yang tepat untuk mencapai tujuan pedagogik. Technological Pedagogical Content Knowledge (TPACK) yang merupakan gabungan dari pengetahuan-pengetahuan dasar tersebut yang diaplikasikan dalam sebuah pembelajaran (Rosyid, 2016).

Kerangka TPACK diatas dapat dijadikan sebagai kerangka teori dan konsep dalam mengukur kesiapan guru dalam proses pembelajaran dikelas yang berfungsi sebagai sebuah teori dan konsep pendidik untuk mengukur kesiapan guru dalam mengajar secara efektif dengan teknologi (Rosyid, 2016). Menurut Rahmadi (2019) pada penelitiannya yang terpapar pada Tabel 1. TPACK ini merupakan pengetahuan tentang penggunaan teknologi yang tepat yang bisa disesuaikan untuk mengajarkan konten fisika dengan baik (Rahmadi, 2019).

Penggabungan dari beberapa unsur hingga menjadi TPACK ini penting dimiliki oleh seorang guru, karena TPACK ini merupakan suatu konsep yang harus dimiliki seorang guru untuk mencapai suatu proses pembelajaran yang maksimal. TPACK dapat mengintegrasikan teknologi, pedagogik dan isi, yang diterapkan sesuai dengan konteks pembelajaran. TPACK menekankan hubungan antara teknologi, isi kurikulum atau dapat dikatakan konten pembelajaran, dan pendekatan pedagogik yang berinteraksi satu sama lain untuk menghasilkan pembelajaran berbasis teknolologi, informasi, dan komunikasi. Pengajaran yang berkualitas membutuhkan suatu pemahaman yang kompleks yang saling berhubungan diantara tiga sumber utama tersebut, yakni teknologi, pedagogik, dan konten pembelajarannya yang harus diterapkan secara bersamaan sesuai dengan konteksnya (Feladi \& Puspitasari, 2018)

\section{Penggunaan Google Apps dalam Pembelajaran}

Google Apps merupakan sebuah layanan yang disediakan google dan dapat diakses secara gratis. Syarat utama penggunaan google apps ini adalah memiliki akun google (Dermawan, Sari, \& Padilah, 2019). Google adalah mesin pencari yang digunakan individu untuk memperoleh informasi yang dibutuhkan secara praktis. Google membantu guru dalam proses pembelajaran untuk menyampaikan konten pembelajaran. Google Apps dalam pembelajaran sebagai perangkat digital yang mendukung penggunaan untuk tujuan pendidikan (Odewumi \& Ahmed, 2019, p. 35)

Google Apps dalam pembelajaran merupakan solusi teknologi informasi yang dapat digunakan sebagai media berkomunikasi dan berkolaborasi antara peserta didik dengan guru ataupun peserta didik dengan peserta didik lainnya. Penggunaan Google Apps untuk pembelajaran ini dapat digunakan untuk memperoleh informasi, membuat dokumen, membuat formulir, membuat soal tes, spreadsheet, presentasi, berkolaborasi, dan yang lainnya. Guru dapat meng-upload materi pembelajaran, tugas, forum diskusi, kuis, begitupun peserta didik dapat mengakses apa yang di-upload oleh guru (Widodo, 2017, p. 2).

Penggunaan Google Apps pada pembelajaran tidak sulit digunakan bahkan untuk pengguna baru, karena tampilannya yang mudah diikuti oleh peserta didik, sehingga dengan penggunaan media pembelajaran Google Apps ini dapat meningkatkan hasil belajar peserta didik (Brown, 2015) 
Penelitian sebelumnya yang membahas tentang penggunaan Google Apps untuk pembelajaran mengatakan bahwa penggunaan Google Apps lebih baik daripada pembelajaran tanpa menggunakan media google.

\section{KESIMPULAN}

Pada abad ke-21 seorang guru dituntut untuk paham teknologi, karena semakin berkembangnya teknologi pada abad ini menuntut guru untuk memiliki pengetahuan tentang teknologi dan penggunaannya dalam pembelajaran. Kemampuan yang perlu dimiliki oleh seorang calon guru untuk mengemas sebuah pembelajaran antara teknologi, pedagogik, dan konten fisika adalah kemampuan TPACK. Hal tersebut dapat terlihat dengan media pembelajaran yang digunakan, yang mana media tersebut harus mengkemas semuanya kedalam sebuah pembelajaran. Media pembelajaran Google Apps dalam kajian teori yang telah dilakukan dikatakan dapat meningkatkan kemampuan TPACK Calon guru, yang mana hal tersebut dibuktikan dengan pembelajaran yang tidak menggunakan media pembelajaran Google Apps ini hasilnya lebih rendah daripada pembelajaran yang menggunakan media Google Apps.

\section{Daftar Pustaka}

Asyhari, A., \& Silvia, H. (2016). Pengembangan Media Pembelajaran berupa Buletin dalam Bentuk Buku Saku untuk Pembelajaran IPA Terpadu. Jurnal Ilmiah Pendidikan Fisika Al-Biruni, 5(1), 1-13. https://doi.org/10.24042/ipifal biruni.v5i1.100

Brown, M. E. (2015). Learning to Use, Useful for Learning: A Usability Study of Google Apps for Education. Journal of Usability Studies, 10(4), 160-181. http://doi.org/10.5555/2817322.2817 $\underline{327}$

Chotimah, K., \& Hariyatmi. (2017). Gambaran Kemampuan Pedogical Content Knowledge Guru IPA Kelas VII SMP Negeri Se-Kabupaten Sukoharjo. Seminar Nasional Pendidikan Biologi dan Saintek II, 671-678.
Dermawan, B. A., Sari, B. N., \& Padilah, T. N. (2019). Pelatihan Google Apps for Education untuk Guru MTsN di Kabupatem Karawang. ABDIMASKU, 2(1), 18-23. https://doi.org/10.33633/ ja.v2i1.33

Dewi, P. K., \& Budiana, N. (2018). Media Pembelajaran Bahasa: Aplikasi Teori Belajar dan Strategi Pengoptimalan Pembelajaran. Malang: UB Press.

Feladi, V., \& Puspitasari, H. (2018). Analisis Profil TPACK Guru TIK SMA di Kecamatan Pontianak Kota. Jurnal Edukasi dan Penelitian Informatika, 4(2), 204-210. http://dx.doi.org/ 10.26418/jp.v4i2.29616

Gora, W., \& Sunarto. (2010). PAKEMATIK Strategi Pembelajaran Inovatif Berbasis TIK. Jakarta: PT. Elex Media Komputindo.

Hadisaputra, S., Hadiprayitno, G., Hakim, A., \& Muhlis. (2018). Pelatihan Peningkatan Keterampilan Guru IPA sebagai Role Model abad 21 dalam Pembelajaran IPA. Jurnal Pendidikan dan Pengabdian Masyarakat, 1(2), 274-277.

Hermanto, R., \& Harimurti, R. (2017). Penerapan Model Pembelajaran Student Centered Learning Berbasis Media Pembelajaran Google For Education Untuk Meningkatkan Hasil Belajar Siswa Pada Bidang Kejuruan Multimedia Smk Negeri 3 Surabaya. Jurnal IT-Edu, 2(1), 23-27.

Koehler, M. J., \& Mishra, P. (2005). Teachers Learning Technology by Design. Journal of Computing in Teacher Education, 21(3), 94-102. https://doi.org/10. $1080 / 10402454.2005 .10784518$

Koehler, M. J., \& Mishra, P. (2009). What is Technological Pedagogical Content Knowledge? Contemporary Issues in Technology and Teacher Eduaction. 9(1), 60-70. https://www.learntechlib.org/ primary/p/29544/

Nasar, A., \& Daud, M. H. (2020). Analisis Kemampuan Guru IPA tentang Technological Pedagogical Content Knowledge pada SMP/MTs di Kota Ende. OPTIKA: Jurnal Pendidikan Fisika, 
4, 9-20. https://doi.org/10.37478/ optika.v4i1.413

Odewumi, M. O., \& Ahmed, M. A. (2019). Fosturing Google Apps For Education (GAfE): The Conceptual Framework. Bulgarian Journal of Scince and Education Policy (BJSEP), 13(1), 34-49.

Rahmadi, I. F. (2019, Maret). Technological Pedagogical Content Knowledge (TPACK): Kerangka Pengetahuan Guru Abad 21. Jurnal Pendidikan Kewarganegaraan, 6(1), 65-74. http://dx.doi.org/10.32493/jpkn.v6i1. y2019.p65-74

Reski, A., \& Sari, K. D. (2020). Analisis Kemampuan TPACK Guru Fisika SeDistrik Merauke. Jurnal Kreatif Online, 8(1), 1-8.

Rosyid, A. (2016). Technology Pedagogical Content Knowledge: Sebuah Kerangka Pengetahuan Bagi Guru Indonesia Di Era MEA. Prosiding Seminar Nasional Inovasi Pedidikan, 446-454.

Saraswati, D. L. (2019). Kelayakan Mobile Learning Media pada Materi Fisika Inti dan Radioaktivitas. JoTaLP: Journal of Teaching and Learning Physics, 4(2), 2534. https://doi.org/10.15575/jotalp. v4i2.5606

Sole, F. B., \& Anggraeni, D. M. (2018). Inovasi Pembelajaran Elektronik dan Tantangan Guru Abad 21. Jurnal Penelitian dan Pengkajian Ilmu Pendidikan, 2(1), 10-18. https://doi.org/10.36312/esaintika.v2i1.79

Supriyadi, Bahri, S., \& Waremra, R. S. (2018). Kemampuan Technological Pedagogical Content Knowledge (TPACK) Mahasiswa Pada Matakuliah Strategi Belajar Mengajar Fisika. Jurnal Inspirasi Pendidikan, 8(2), 1-9. https://doi.org/ 10.21067/iip.v8i2.2632

Suryawati, E., Linggasari, M. N., \& Arnentis. (2017). Technological Pedagogical and Content Knowledge of Biology Prospective Teachers. Biosaintifika: Journal of Biology \& Biology Education, 9(3), 498-505. https://doi.org/ $\underline{10.15294 / \text { biosaintifika.v9i3.11270 }}$
Teknowijoyo, F. (2020). Media Pembelajaran Berbasis Google Edukasi untuk Meningkatkan Hasil Belajar Peserta Didik. Journal of Curriculum Indonesia, 1 , 30-38.

Widodo, S. (2017). Implementing Google Apps for Education as Learning Management System in Math Education. Journal of Physics: Conference Series, 895 (012053) 1-5. https://doi.org/10.1088/17426596/895/1/012053

Yulianisa, Rizal, F., Oktaviani, \& Abdullah, R. (2018). Tinjauan Keterampilan Abad 21 (21st Century Skills) di Kalangan Guru Kejuruan (Studi Kasus: SMK Negeri 2 Solok). CIVED Jurusan Teknik Sipil, $X X(X), 1-8$. 